\title{
Erratum to: TNFR1 absence protects against memory deficit induced by sepsis possibly through over-expression of hippocampal BDNF
}

\author{
Allan C. Calsavara • Frederico M. Soriani • \\ Leda Q. Vieira • Priscila A. Costa • Milene A. Rachid • \\ Antônio L. Teixeira
}

Published online: 5 October 2014

(C) Springer Science+Business Media New York 2014

Erratum to: Metab Brain Dis (2014)

DOI 10.1007/s11011-014-9610-8

The original version of this article unfortunately contained a mistake. In the original publication of this manuscript, the name of the last author is incorrectly listed in the main text as 'Antônio L. Teixiera'. The correct surname for the last author of this publication is Teixeira.

The online version of the original article can be found at http://dx.doi.org/ 10.1007/s11011-014-9610-8.

\footnotetext{
A. C. Calsavara $(\bowtie) \cdot$ P. A. Costa $\cdot$ A. L. Teixeira Interdisciplinary Laboratory of Medical Investigation,

School of Medicine, Universidade Federal de Minas Gerais,

Belo Horizonte, MG, Brazil

e-mail: allancalsavara@gmail.com
}

\section{A. C. Calsavara}

School of Medicine, Universidade Federal de Ouro Preto, Ouro

Preto, MG, Brazil

F. M. Soriani $\cdot$ L. Q. Vieira $\cdot$ M. A. Rachid

Institute of Biological Sciences, Universidade Federal de Minas

Gerais, Belo Horizonte, MG, Brazil 